\title{
A Produção Camponesa de Hortaliças no Assentamento Eldorado II Grupo- Fetagri: Entraves e Desafios
}

The Peasant Production of Vegetables in the Eldorado I/ Group- Fetagri Settlement: Barriers and Challenges

La Producción Campesina de Hortalizas en El Grupo Eldorado II - Asentamiento de la Fetagri: Barreras Y Desafíos

Carina Moreira Silva Licenciada em Educação do Campo, UFGD, Brasil. ckarinamoreira96@gmail.com

Rodrigo Simão Camacho Professor Doutor, UFGD, Brasil rodrigocamacho@ufgd.edu.br

Cristiano Almeida da Conceição

Doutorando em Geografia, UFGD, Brasil cristiano.conceicao014@academico.ufgd.edu.br 


\title{
Revista Científica ANAP Brasil
}

\author{
ISSN 1984-3240 - Volume 13, número 30, 2020
}

RESUMO

A agricultura camponesa mais do que uma atividade agroecológica é uma forma de relação que a comunidade estabelece entre as pessoas que vivem nesse meio, além de ser um elemento importante para toda a sociedade, pois é através da prática dessa agricultura que os camponeses tiram seu próprio sustento, o sustento da comunidade e produzem alimento para toda a sociedade, construindo uma sociedade mais sustentável. Esse artigo tem como objetivo mostrar um pouco mais sobre a agricultura camponesa e procura compreender quais são as dificuldades encontradas pelos mesmos. Temos como recorte de análise, os produtores de hortaliças no Assentamento Eldorado II (Grupo FETAGRI-MS) do Município de Sidrolândia-MS, que com muito esforço e como forma de resistência mantém sua produção mesmo diante da dificuldade que enfrentam.

PALAVRAS-CHAVE: Agricultura Camponesa. Limites. Produtores rurais.

\section{ABSTRACT}

Peasant agriculture is more than an agro-ecological activity, it is a form of relationship that the community establishes among the people living in this environment, besides being an important element for the whole of society, since it is through the practice of this agriculture that peasants take their own livelihood, livelihood of the community and produce food for the whole society, building a more sustainable society. This article aims to show a little more about peasant agriculture and seeks to understand the difficulties encountered by peasants. We have as a cut-off analysis, vegetable producers in the settlement Eldorado II (Group FETAGRI-MS) of the Municipality of Sidrolândia-MS, which with great effort and as a form of resistance maintains its production even in the face of the difficulty they face.

KEYWORDS: Peasant Agriculture. Difficulty. Rural Producers

\section{RESUMEN}

La agricultura campesina, más que una actividad agroecológica, es una forma de relación que la comunidad establece entre las personas que viven en ese entorno, además de ser un elemento importante para toda la sociedad, ya que es a través de la práctica de esta agricultura que los campesinos se apoderan de ellos. medios de vida, medios de vida de la comunidad y producir alimentos para toda la sociedad, construyendo una sociedad más sostenible. Este artículo tiene como objetivo mostrar un poco más sobre la agricultura campesina y busca comprender cuáles son las dificultades que enfrentan. Tenemos como parte de análisis a los productores de hortalizas en el Asentamiento Eldorado II (Grupo FETAGRI-MS) del Municipio de Sidrolândia - MS, que con mucho esfuerzo y como forma de resistencia mantiene su producción incluso ante la dificultad que enfrentan.

PALABRAS CLAVE: Agricultura campesina. Límites. Productores rurales. 


\section{1 - INTRODUÇÃO}

A agricultura camponesa é responsável por evitar o êxodo rural proporcionando a permanência da família camponesa no campo, além disso, desempenha um importante papel socioeconômico e cultural na sociedade ao produzir alimentos de maneira agroecológica e sustentável. Mas apesar disso ela também apresenta alguns entraves e desafios, e as discussões acadêmicas sobre estes problemas é importante para que possamos construir pilares mais fortes para outra forma desenvolvimento baseada na agricultura camponesa.

Dessa forma, a ideia do presente trabalho veio de acordo com a realidade dos produtores do assentamento Eldorado II, Município de Sidrolândia - MS, que tentam diversas formas de organização para solucionar o problema que os acompanham desde quando começaram com o cultivo de hortaliças, e o que eles mais querem é agregar valor aos seus produtos, conquistar espaço para vender sua produção e, assim, conseguir renda suficiente para sua permanência no campo. Foi, então, que surge a necessidade de pesquisar e compreender qual é a dificuldade que os produtores enfrentam em relação as suas produções?

Ao começar pesquisar com os produtores e fazer algumas perguntas sobre suas produções, eles afirmam que não tem dificuldades nenhuma em produzir, tudo que planta nasce e reproduz, continuamos na conversa para identificar se existe algum impasse, e ao perguntar qual a dificuldade maior enfrentada por eles, à resposta foi à mesma, possuem problema em relação ao escoamento das produções.

O estudo verificou que entre alguns fatores decisivos que poderia ser apontado como entrave está: a falta de transporte, que deixam as mercadorias na mão do atravessador, e o prejuízo na mão dos produtores.

\section{2 - METODOLOGIA}

A metodologia da pesquisa se deu através de questionários com perguntas objetivas e conversas informais com os produtores rurais por meio da observação-participante, tendo em vista que a autora é moradora no assentamento. Foram entrevistados 04 produtores no assentamento Eldorado Il do grupo da Federação dos Trabalhadores na Agricultura do estado de MS (FETAGRI - MS) ${ }^{1}$, pois esses produzem para comercializar, os demais produzem somente para o próprio consumo e, muitos deles, praticam a criação de gado.

\section{3 - RESULTADOS E DISCUSSÃO}

\section{1-CARACTERIZAÇÃO DO MUNICÍPIO DE SIDROLÂNDIA}

O município de Sidrolândia está localizado a 67 quilômetros da capital Campo Grande, possui limites ao norte com o município de Terenos, ao sul com o município de Rio Brilhante, a leste com o município de Campo Grande e a oeste com os municípios de Maracaju e Dois Irmãos do Buriti (conforme figura 1).

\footnotetext{
${ }^{1}$ A FETAGRI é uma entidade filiada à Confederação Nacional de Trabalhadores na Agricultura (CONTAG), fundada em 23 de fevereiro de 1979 com o objetivo de lutar por uma reforma agrária democrática. (informação verbal, 2018).
} 
O clima é classificado como sendo tropical úmido, não tendo estação de seca definida, no inverno a ocorrência de geadas é comum entre julho a novembro. Segundo o Plano de Desenvolvimento- PDA (2010, p.20):

No município de Sidrolândia, onde se situa o assentamento, não possui estação meteorológica, o referencial foi obtido da avaliação climática na região de Campo Grande, que apresenta oscilações entre $17^{\circ} \mathrm{C}$ de mínima e $30^{\circ} \mathrm{C}$ de máxima no período de janeiro a maio, podendo chegar até $35 \mathrm{C}$ no verão.

Figura1: Localização do Município de Sidrolândia

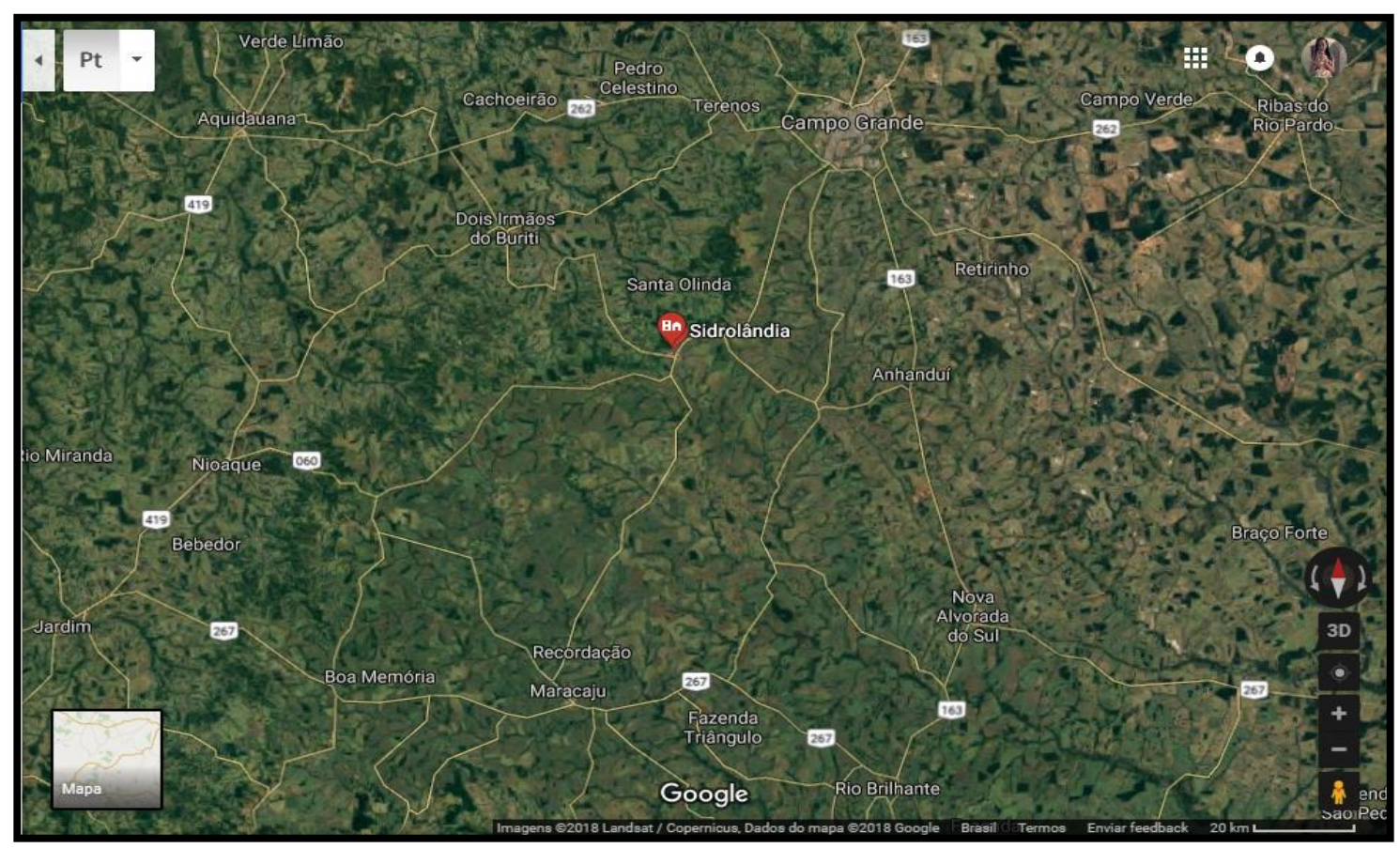

Fonte: Google Maps (2019).

Sidrolândia por ser um município campeão do Estado em números de assentamentos rurais e também por ser o município que mais cresce em Mato Grosso do Sul, é considerado um lugar de oportunidades, aumentando o número de migrantes que vem em busca de uma melhoria de vida, o município conta com indústria de alimentos, solo produtivo, infraestrutura de armazenagem e escoamento (PDA, 2010). Estes fatores juntamente com a criação de vários assentamentos foi um ponto fundamental para elevar a economia de Sidrolândia.

\section{2 - SURGIMENTO DO ASSENTAMENTO ELDORADO II}

O assentamento Eldorado II (Mapa de localização na figura 2) passou por um processo histórico/político profundo até ser transformado em assentamento de reforma agrária. Antes de tudo era conhecido como fazenda Eldorado localizada no Estado de Mato Grosso do Sul, Município de Sidrolândia, o assentamento tem cerca de 7.016,3121 hectares parcelados em 777 lotes de aproximadamente 9.0 hectares cada (PDA, 2010). 


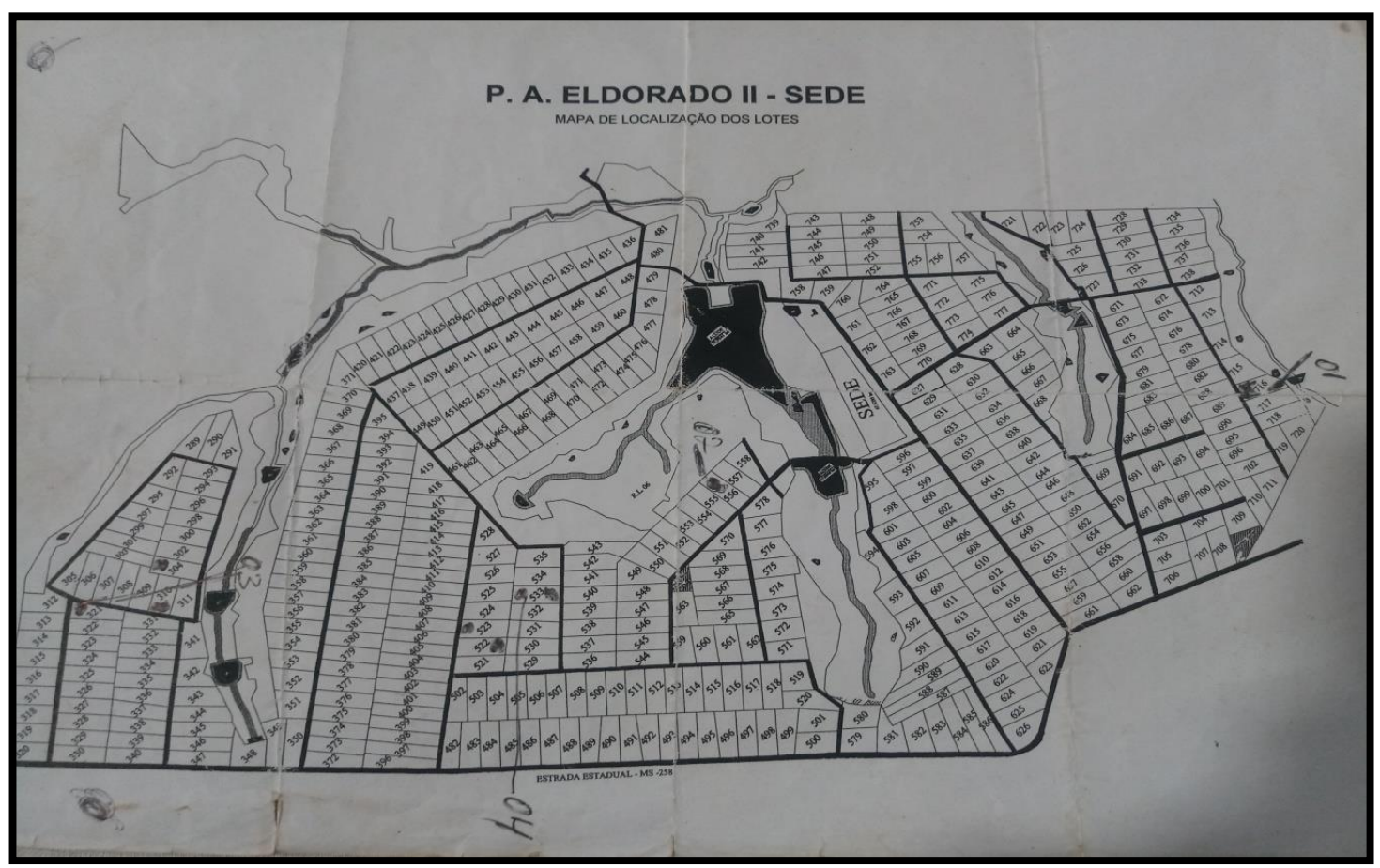

Fonte: INCRA (2019).

O assentamento Eldorado II, objeto desta pesquisa, foi criado através da portaria n 045 de 27/12/2005, beneficiando as famílias acampadas pela Federação dos Trabalhadores na Agricultura do Estado de Mato Grosso do Sul (FETAGRI - MS). Durou um ano desde a repartição dos lotes até a entrega dos mesmos, o sorteio ocorreu no dia 14 de dezembro de 2006 . A luta das famílias assentadas apenas começou ao adquirirem seus lotes, pois sem muitas condições para investimentos, entraram nos lotes sem nada de recursos, foram atrás de créditos para produção, e ainda corrigir solos improdutivos da antiga fazenda.

Sempre fomos atrás dos nossos direitos, não queremos somente terra cortada todos os assentados devem ter seus direitos ao que diz respeito às políticas públicas que vem complementar a reforma agrária que são: os créditos rurais, comercialização, saúde, assistência técnica e não menos importante educação no campo para nossos filhos. (entrevista realizada com Fabrício² concedida em 06/04/2018).

A infraestrutura no assentamento era bem fraca, foram abertas estradas e travessões, mas não era de boa qualidade, passaram dificuldades em relação à energia elétrica, tinham 04 poços artesianos, mas não atendia toda a demanda, não pegava sinais de telefone/celular, além da distância do posto e escola, localizados na sede do assentamento Eldorado II, com essa distância

${ }^{2} \mathrm{O}$ nome é fictício para preservar a identidade dos entrevistados. 
os mais prejudicados eram os alunos que passavam longos períodos de tempo dentro de ônibus escolares para ter acesso à escola, sem contar que as estradas eram quase impossíveis de transitar, e piorava ainda mais quando chovia. Com o passar do tempo e com muita luta dos assentados em buscar melhorias para suas vidas, muitos conseguiram superar e progrediram. Mas como sabemos que os dois primeiros anos são os mais difíceis, que é o início, quando o assentado passa pelo processo de estruturação do lote, nessa fase investe capital, produz pouco, consome muito e não vê retorno algum. E foi nesse período justamente com a falta de Assistência Técnica Rural (ATER), de recursos para o investimento que veio o sofrimento de muitos proprietários, e assim não tiveram outra saída a não ser a desistência dos seus lotes. ${ }^{3}$

Passamos muito sufoco na época do acampamento, ainda mais que viemos pra debaixo do barraco com toda a família, a estrutura não era boa, tivemos muitas dificuldades e para se manter, tive que sair pra trabalhar fora, senão nem o sustento para família eu conseguia, fiquei dois anos acampando e mais ou menos 1 ano e meio trabalhando fora, entre safra na usina e trabalho em fazenda. Logo em seguida saiu o sorteio dos lotes, peguei minha terrinha e o primeiro passo foi cercar, investi todos os meus trocadinhos e hoje já estou com o lote todo estruturado e mexendo com hortaliças. No começo sofri demais e até cheguei a pensar em desistir, mais como meu sonho sempre foi ter um lugarzinho pra eu mexer na terra, me mantive firme e passei por cima das dificuldades, e não me arrependo. (entrevista realizada com Marcelo ${ }^{4}$ concedida em: 07/04/2018)

As famílias que resistiram e tiveram paciência, nos dias de hoje já estão com suas propriedades estruturadas, possuem poços semi-artesianos, energia elétrica instalada, acesso as políticas públicas e linhas de créditos. A principal atividade econômica desenvolvida pelos assentados é a agricultura, sendo que os produtos mais representativos são da produção de hortaliças. Entretanto, ainda enfrentam dificuldades relacionadas ao meio de produção, falta de ATER adequadas as necessidades específicas, e dificuldade na comercialização ${ }^{5}$ (escoamento da produção de suas hortaliças).

\section{3 - A AGRICULTURA CAMPONESA}

Quando falamos em agricultura camponesa temos que ter ideia de que além de ser um jeito de produzir alimentos de boa qualidade no campo, é também uma forma diferenciada de se viver em comunidade, onde as famílias sobrevivem somente de sua terra sem precisar sair do campo para trabalhar como assalariado nas cidades. Segundo Carvalho e Costa (2012, p. 28): “A agricultura camponesa é a principal forma de garantir a soberania alimentar e a produção agroecológica, é o modo de fazer agricultura e de viver das famílias que, tendo acesso a terra e aos recursos naturais que ela suporta, resolvem seus problemas reprodutivos por meio da reprodução rural". A família camponesa com participação das comunidades tem um laço forte

\footnotetext{
${ }^{3}$ Informações obtidas em observação- participante e em conversas informais com os assentados.

${ }^{4} \mathrm{O}$ nome é fictício para preservar a identidade dos entrevistados.

${ }^{5}$ Informações obtidas em observação - participante.
} 


\section{Revista Científica ANAP Brasil}

ISSN 1984-3240 - Volume 13, número 30, 2020

e importante, pois eles se preocupam com a cultura e diversidade de suas produções, sempre buscando a resistência, pois vivem sob pressão do mercado capitalista que quer desaparecer com a agricultura camponesa. Ela tem como importância a reprodução social dos seus trabalhadores diretos, que são os próprios integrantes da família, apresentam um objetivo diferente daquelas das empresas capitalistas que se baseiam no assalariamento para obtenção de lucro (CARVALHO; COSTA, 2012).

A agricultura camponesa pode ser pensada como uma relação social não-capitalista é uma forma de produzir e fazer circular as mercadorias simples, e a transformação desse excedente na forma de dinheiro se dá no intuito dos produtores adquirirem outras mercadorias para satisfação de suas necessidades, deixando ótimos alimentos para os consumidores, além de cuidar e proteger a natureza usando na terra práticas tradicionais, saberes e experiências vivenciadas pelos camponeses, visando assim um futuro sustentável, há também diversificação e rotação de cultivo. Ela desempenha um importante papel socioeconômico na sociedade e nos grupos familiares, além de fornecer serviço para os jovens, diminuindo o êxodo rural e proporcionando a permanência da família rural no campo (OLIVEIRA, 2007; CAMACHO, 2014).

Mesmo sendo a principal produtora de alimentos, a agricultura camponesa no país enfrentou, e enfrenta, desde o seu surgimento no período colonial até a época atual, os mais distintos tipos de empecilhos: dificuldades políticas do acesso à terra, várias formas de pressão e repressão para a sua subalternização às empresas capitalistas, exploração continuada da renda familiar por diversas frações do capital, indução direta e indireta para a adoção de um modelo de produção e tecnológico que lhe era e é preconceituosa a ideologia dos camponeses, sempre considerados à margem do modo capitalista der fazer agricultura. (CARVALHO; COSTA, 2012, p. 32).

A agricultura camponesa é a oposição a agricultura capitalista, pois no modo capitalista de fazer agricultura é grande a concentração das terras e como resultado tem o privilégio da produção em escala, isso requer grande extensão continua de área para a prática do monocultivo e técnicas como uso intensivo de insumos químicos que maximizam a produção e combinado com a mecanização alteram e diversificam as formas de exploração de trabalho. No entanto, o modo de fazer agricultura camponesa não está separado do modo de viver da família, pois é preciso considerar que apresenta diversas características como os saberes e as características de produção vivenciada pelas famílias camponesas, ás práticas tradicionais, a troca de conhecimento entre vizinhos, parentes e compadres, o uso da terra ocorre de maneira direta pela família, há diversificação de cultivos, e, enfim, existe rendimento monetário para a família (CARVALHO; COSTA, 2012).

Entretanto, a pesar de defendermos a agricultura camponesa, não temos somente a existência desse conceito para designar os mesmos sujeitos sociais. $O$ debate em torno do termo "camponês", bem como o de "agricultura familiar", tem ocupado os discursos na atualidade, essa discussão vem acompanhada do termo agricultura em pequena escala no Brasil, que tem várias definições e pode ser confundida pela diversidade de categoria utilizada para definir o que é camponês. Segundo Ribeiro (2012, p.1): “A história dos camponeses não foi uma história formada apenas no século XX, mas sim uma construção histórica desde sistema feudal em que 
os servos já começaram a repudiar as imposições dos senhores e procuravam viver livres". Entende-se com isso que os camponeses buscavam conquistar a liberdade, querendo um espaço dentro da sociedade resistindo à força de seus dominantes, com isso nasceu o movimento de luta e resistência para terem acesso às terras e cultivarem suas lavouras. Esses pressupostos demarcam a história dos camponeses na luta pelo trabalho livre de especulação capitalista, mas, por outro lado, surgem teorias tentando camuflar o passado histórico da construção da agricultura camponesa, mudando o nome para agricultura familiar, e, de certa forma, procurando adequar os camponeses ao modo capitalista de produção, porém esses trabalhadores não são formados de relações sociais capitalistas, porque eles surgiram exatamente na resistência a esse sistema (RIBEIRO, 2012).

O campesinato é a contraposição às relações sociais no capitalismo, pois ele se reproduz com trabalho familiar sem exploração do trabalho, geração de mais-valia e acumulação de capital.

Nas sociedades modernas-capitalistas, terra, família e trabalho são categorias pensadas separadamente. São pensadas em si mesmas. A terra não tem relação com a família e com o trabalho, tendo em vista que a mesma é uma coisa ou mercadoria. Enquanto as sociedades camponesas formam um modelo relacional entre as categorias, relações sociais e pessoas, as sociedades modernas formam um modelo individual constituído por um agregado de indivíduos em contrato. (CAMACHO, 2014, p. 10).

É possível perceber o uso da expressão agricultura familiar por parte dos agricultores do assentamento Eldorado II município de Sidrolândia-MS. Quando os entrevistados são indagados como eles se consideram, são apontadas três opções sendo elas: Agricultura Camponesa; Agricultura Familiar e Agricultura Comercial, todos eles se consideram como agricultores familiares.

Pedimos a um dos entrevistados uma justificativa para entender o motivo pela qual ele teria respondido agricultura familiar. "É de onde tiro minha subsistência, aprendi a trabalhar foi nisso, eu sempre me considerei um agricultor familiar, trabalho desde pequeno no meio rural e toda minha família trabalha unida, quando preciso trocamos dias de serviços e até mesmo alimentos". (Entrevista realizada com Alfredo ${ }^{6}$, concedida em 03/04/2018).

Consideramos que o motivo pela qual eles usam esse termo, é pelo fato de já vir sendo adquirido desde as políticas públicas, ou seja, todos os produtores são reconhecidos como agricultores familiares, com toda essa influência dos órgãos públicos eles passam a se auto-reconhecerem como tal.

\section{4 - A PRODUÇÃO CAMPONESA DE HORTALIÇAS NO ASSENTAMENTO ELDORADO II}

O assentamento Eldorado II tem como característica marcante em suas áreas a diversidade nos cultivos como: produção de frutas e verduras, especialmente a salsa, almeirão, cebolinha e alface. Porém, tem áreas, também, com a monocultura da produção de milho e soja. Como pode ser observado na imagem a seguir (figura3).

${ }^{6}$ Nome fictício. 
Figura 3: Hortaliças cultivadas(salsa, cebolinha, alface e almeirão)
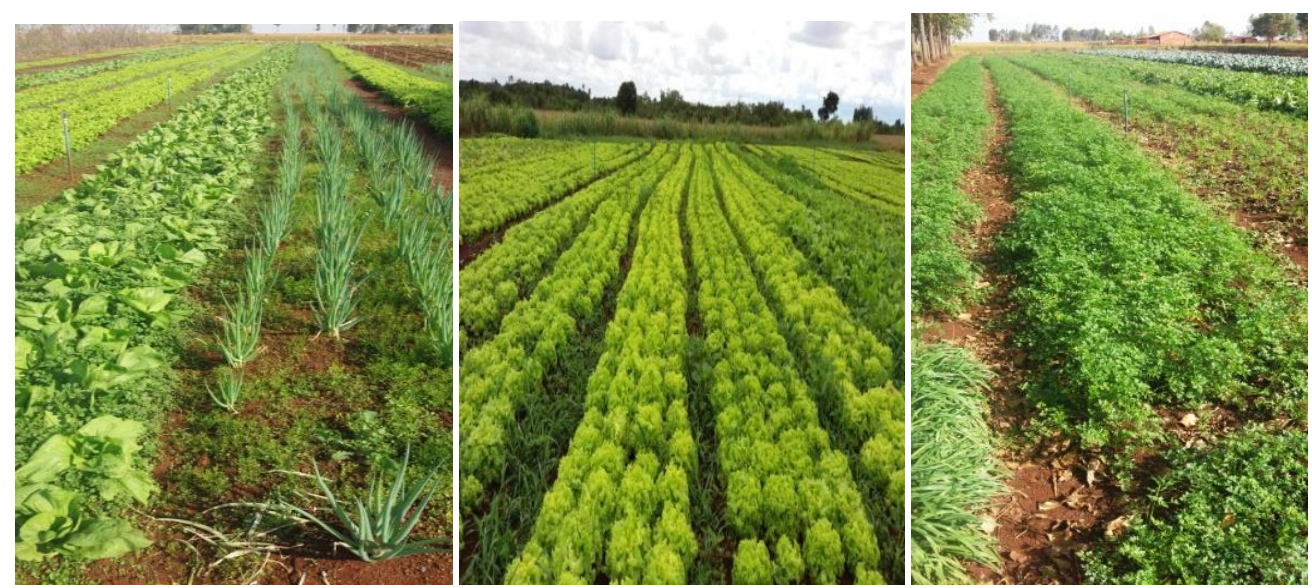

Fonte: Autores (2018).

O processo de produção de hortaliças, além de ser uma atividade econômica, tem presente às raízes familiares, onde os produtores trabalham da maneira que aprendeu com as outras gerações passadas e, consequentemente, os filhos aprendem a trabalhar da mesma forma. Os produtores de hortaliças são conhecidos popularmente por "horteiros" ou verdureiros e trabalham a partir dos processos que inclui a preparação do solo, o plantio, o crescimento e, por fim, a colheita.

O preparo da terra é feito com a ajuda de um motocultivador conhecido como "tobata" ou "tratorito", utilizado para revolver o solo. Os canteiros são erguidos manualmente, o plantio também é feito manualmente. Os produtores compram as bandejas das mudas vindas de Campo Grande e armazenam dentro dos reservatórios de água até que o canteiro esteja pronto, ainda no preparo é utilizado cama de frango ${ }^{8}$ e adubos orgânicos. A irrigação é feita através de redes de encanamento instaladas na horta por gotejamento. A colheita é feita de modo tradicional, ou seja, manualmente sem a ajuda de maquinário ou algum tipo de equipamento que favoreça o agricultor. Vejamos a figura 4:

\footnotetext{
${ }^{7}$ Horteiro é o nome dado aos agricultores que cultivam hortaliças.

${ }^{8}$ Material utilizado para forrar o piso dos galpões, que pode ser de maravalha, palha de arroz, feno de capim, sabugo de milho triturado ou serragem com as fezes, urina, restos de ração e penas que se misturam com esse material (EMBRAPA, 2018).
} 


\section{Revista Científica ANAP Brasil}

ISSN 1984-3240 - Volume 13, número 30, 2020

\section{Figura 4: Preparo da terra para o plantio}

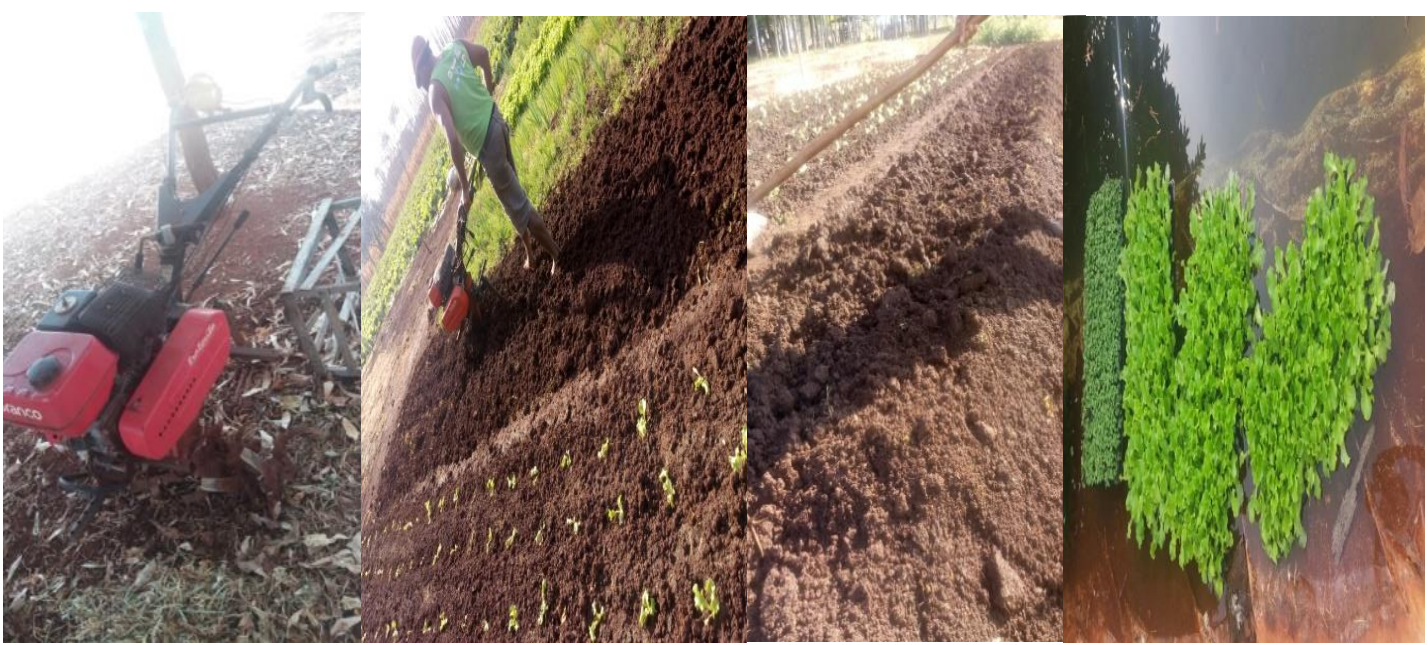

Fonte: Autores (2018).

Após a colheita é feita a higienização das verduras e legumes, e armazenadas em caixas plásticas ou em caixotes de madeira que os agricultores compram a 0,80 centavos a unidade, é colocado por caixa o total de 18 pés de alface, mas como eles trabalham com caixa grande, é colocada uma quantidade de 36 pés, o equivalente a duas caixas, quando falta caixa eles colocam a alface em caixote mesmo. Dependendo do tamanho do maço industrial de cebolinha, uma caixa comporta até 80 , a salsa cabe de 40 a 50 maços por caixa, e o almeirão é colocado nos caixotes um total de 15, dependendo do seu tamanho. Conforme observamos na figura 5.

Figura 5: Processo de colheita e higienização das hortaliças

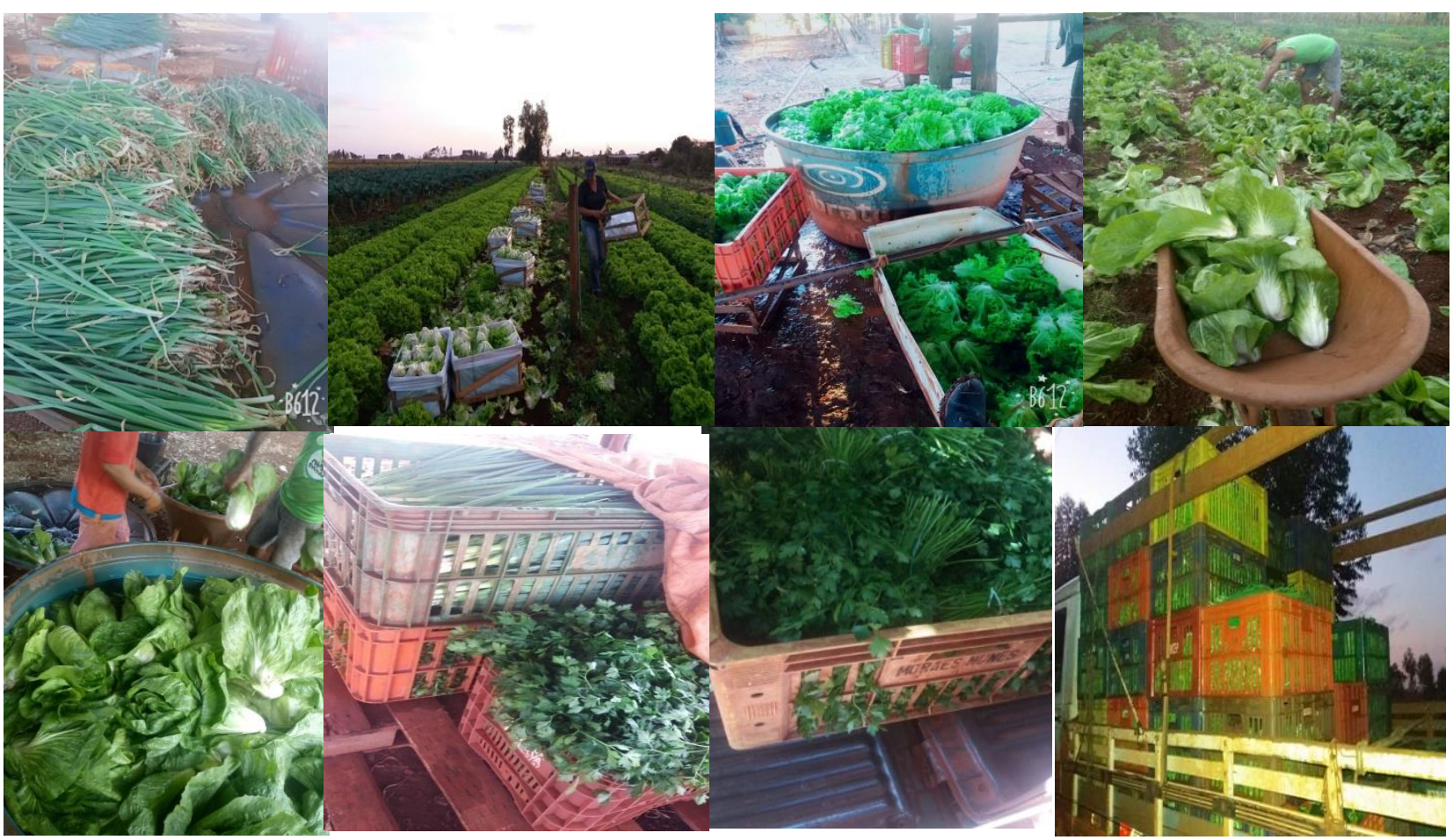

Fonte: Autores (2018). 


\section{Revista Científica ANAP Brasil}

ISSN 1984-3240 - Volume 13, número 30, 2020

Os produtores relatam que não encontram dificuldades na produção, abarreira encontrada está somente no escoamento da produção que é feita através de atravessadores ${ }^{9}$. Questionando os motivos pelas quais eles não comercializam em programas institucionais como o Programa de Aquisição de Alimentos (PAA) ${ }^{10}$ e Programa Nacional de Alimentação Escolar (PNAE) ${ }^{11}$, eles responderam que para conseguir realizar as entregas é preciso de uma associação ou uma cooperativa organizada que funcione bem, além de planejamentos e projetos que, muitas das vezes, não são aprovados. Tem, também, a questão da Declaração de Aptidão ao Pronaf (DAP) que é o documento que os agricultores precisam para ter acesso às políticas públicas, e muitas estão bloqueadas por ter vencido o prazo de 03 anos e os produtores não conseguiram revalidar, e para acessar todos os benefícios que o documento garante é preciso que a DAP esteja ativa. Ainda disseram que já tentaram fazer entrega nas feiras, mas como a produção deles se tornou grande em relação à quantidade que é vendida e por não ter como transportar até o local, essa estratégia acaba não funcionando e, consequentemente, os leva a perderem produtos e a única saída para não perder o produto na horta é comercializar para o atravessador ${ }^{12}$.

No intuito de compreender como os produtores se articulam para fazer com que suas produções de hortaliças cheguem até o comércio, foraminquiridos 04 agricultores em questionários com 27 questões objetivas. Os produtores residem na Eldorado há 12 anos e já acessaram as linhas de créditos do Programa Nacional da Agricultura Familiar (PRONAF) a média de idade deles varia entre 47 a 58 anos, 02 deles possuem o Ensino Fundamental completo e 02 possuem o Ensino Fundamental incompleto. Eles trabalham com um total de 03 e 04 pessoas na produção da horta por propriedade e utilizam somente a mão-de-obra familiar.

Ao serem indagados se eles possuíam transportes de carga. De acordo com as respostas dos produtores somente 01 respondeu que sim, os outros 03 disseram que não possuem. Isso dificulta bastante o processo de circulação de suas mercadorias, pois não vêem alternativas a não ser aceitar a "ajuda" ${ }^{13}$ dos atravessadores para fazer com que suas produções consigam chegar até o comércio.

Quando perguntamos sobre a renda, todos os 04 entrevistados responderam que a renda total provém da horticultura, com uma média de 02 salários mínimos obtidos através do cultivo, 01 deles, além da horticultura arrenda o lote para plantio de soja e milho. Os produtos mais vendidos apontados por eles são: cebolinha, almeirão, salsa e alface. Produzem em média por semana cerca de 100 maços de cebolinha, 300 maços de salsa, 50 maços de almeirão totalizando 450 maços, e em torno de 20 caixas de alface,

\footnotetext{
${ }^{9}$ Relato construído por meio de observação-participante.

${ }^{10}$ É uma ação do governo federal criado para fortalecer a agricultura camponesa e colaborar com o enfrentamento da pobreza no Brasil. Disponível em: <https://www.bing.com/search?FORM=SLBRDF\&PC=SL10\&q=paa\#>. Acesso em: 20 jul. 2018.

${ }_{11}$ Programa que oferece alimentação escolar e ações de educação alimentar e nutrição a estudantes de todas as etapas da educação básica pública. Disponível em: <http://www.fnde.gov.br/programas/alimentacao-escolar>. Acesso em: 20 jul. 2018 .

${ }^{12}$ Nome popular do indivíduo responsável por fazer a intermediação entre o produtor e o mercado. Ele é responsável por comprar a mercadoria dos pequenos produtores e revender esta mercadoria comprada no mercado por preço mais alto para obter lucro.

13 Palavra dos entrevistados.
} 
Perguntamos ainda quem comprava os produtos deles, e todos responderam que é o atravessador. É possível observar no dia-a-dia dos agricultores a sua indignação em relação à remuneração sobre seus produtos vendidos, pois quando pergunto se estão satisfeitos com o preço pago, eles dizem que não. Na feira vendem a 2,00 cada maço e 1,50 cada pé de alface e no mercado a produção levada pelo atravessador sai a 0,70 centavos. Ressaltam eles que apesar das diferenças de valores, o fator pela qual ainda estão entregando para atravessador é a questão de transporte.

O atravessador nunca cumpre o prometido e ainda se aproveita da falta de organização dos agricultores rurais para adquirir seus produtos a um preço super baixo e revender ao atacado ou varejo por um preço estipulado pelo próprio atravessador, ele consegue fazer isso pelo simples fato de ter uma grande concentração de mercadorias em mãos, facilitando assim a negociação com o cliente. (entrevista realizada com Alfredo ${ }^{14}$, concedida em 03/04/2018).

O atravessador é considerado uma figura desligada do processo produtivo, ou seja, ele não produz nada e obtém seu lucro comprando a prazo do agricultor e vendendo a vista ao consumidor final ou até mesmo para outro intermediário, e acaba ficando sempre com a maior parte do lucro. Este processo é o que denominamos da subordinação da renda camponesa ao capital, processo em que o camponês produz a mercadoria com seu trabalho, mas na venda parte de sua renda é apropriada pelo capital (OLIVEIRA, 2007). Os agricultores ficam dependentes dele, pois não tem muitos conhecimentos sobre comercialização e há uma distância entre produção e comercialização, sendo que ainda falta o transporte de carga. Estes fatores fazem com que os produtores fiquem a mercê desta situação.

O atravessador é o sujeito principal que intermedia o processo entre produção e comercialização, pois é através dele que os agricultores do assentamento Eldorado II conseguem escoar a produção, só ele tem controle de transportar e vender essas mercadorias. Ele leva para a capital (Campo Grande) e vende para a Quitanda do Produtor, Mercado São João e Mercado Arnaldo. A comercialização não é feita somente por ele, ela passa por etapas até que chegue ao consumidor final.

\section{4 - CONSIDERAÇÕES FINAIS}

Para os produtores do assentamento Eldorado II a atividade agrícola é de muita importância, principalmente porque é da mesma que eles tiram o sustento da família e toda transformação que ocorre atinge todos os produtores. Consequentemente se houver mudanças na forma deles escoar suas produções, poderá haver também transformações fundamentais para uma melhor valorização dessa atividade.

Um dos fatores que se observou na pesquisa é que a comercialização é o principal problema enfrentado pelos produtores e o atravessador é o responsável por essa problemática, pois este faz com que o produto fique mais caro, fazendo com que o produtor não usufrua de um preço aceitável. $O$ resultado desta pesquisa evidencia a insatisfações dos produtores em relação às

14 O nome da pessoa entrevistada é fictício 
condições vividas por eles, pois está totalmente fora do esperado. Foi observado também que a falta de transporte é um fator negativo para eles, pois se tivessem um meio próprio para estarem transportando toda essa mercadoria, eles não estariam na situação que se encontram. Mas, apesar de toda frustração em relação ao preço, eles não desistem da atividade agrícola e se mantém firmes, pois produzem muito e mesmo com toda essa problemática eles conseguem vender todo o seu produto. Eles estão correndo atrás de trabalhar na forma de cooperativas, criando meios que facilitem a venda dos produtos com a finalidade de melhoria de renda.

Enfim, esta pesquisa representa um primeiro passo para outras pesquisas que possam aprofundar o estudo de caso no assentamento Eldorado II, alguns elementos ficaram de fora pela complexidade das relações e requer aprofundamento em trabalhos futuros. No entanto, o resultado que se obteve através dessa pesquisa é um estímulo a ser pensado e discutido com a possibilidade de soluções para amenizar ou resolver esta situação.

\section{REFERÊNCIAS}

BRASIL, Associação CRESCER. INCRA SR-16. Decreto Estadual n 12.528/08. Plano de Desenvolvimento do PA Eldorado II. Sidrolândia: INCRA, mai. 2010.

CAMACHO, Rodrigo Simão, Algumas considerações acerca do modo de vida camponês, Fórum Ambiental da Alta Paulista, Populações Nativas e Manifestações Culturais, n. 10, p. 16, 2014.

CARVALHO, Horacio Martins de; COSTA, Francisco de Assis. Agricultura Camponesa. In: CALDART, Roseli S. et al. Dicionário da Educação do Campo. Rio de Janeiro: Escola Politécnica de Saúde Joaquim Venâncio; São Paulo: Expressão Popular, 2012, v. 1, p.26-31.

EMBRAPA. Cama de aviário: materiais, reutilização, uso como alimento e fertilizante. Disponível em:<https://ainfo.cnptia.embrapa.br/digital/bitstream/item/67877/1/CUsersPiazzonDocumentsProntos >. Acesso em: 20 jul. 2018.

OLIVEIRA, Ariovaldo Umbelino de. As relações de produção na agricultura sob o capitalismo. In: Modo de produção capitalista, agricultura e reforma agrária. São Paulo: FFLCH/Labur Edições, 2007.

RIBEIRO, José Carlos de Oliveira. Diferenciação entre agricultura camponesa e agricultura familiar. Jan. 2012. Disponível em: $<$ https://www.webartigos.com/artigos/diferenciacao-entre-agriculturacamponesa-e-agricultura-familiar/83089/\#i>. Acesso em: 15 jun. 2018.

SIDROLANDIA. Prefeitura Municipal de Sidrolândia. Disponível em: <www.sidrolandia.ms.gov.br>. Acesso em: 19 fev. 2018. 